SANDIA REPORT

SAND95-8540 • UC-404

Unlimited Release

Printed May 1995

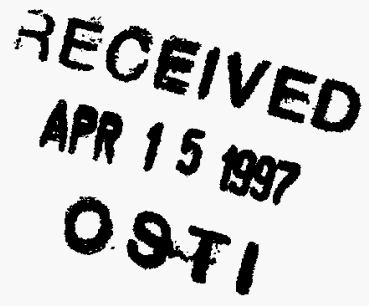

\title{
A Continuous Emissions Monitor for Metals: Field Demonstration of a Prototype Probe
}

William Flower, Larry Peng, Christine Woods, Nina Bergan French, Ken Hencken, Howard Johnsen, Ron Renzi, Dan Trujillo

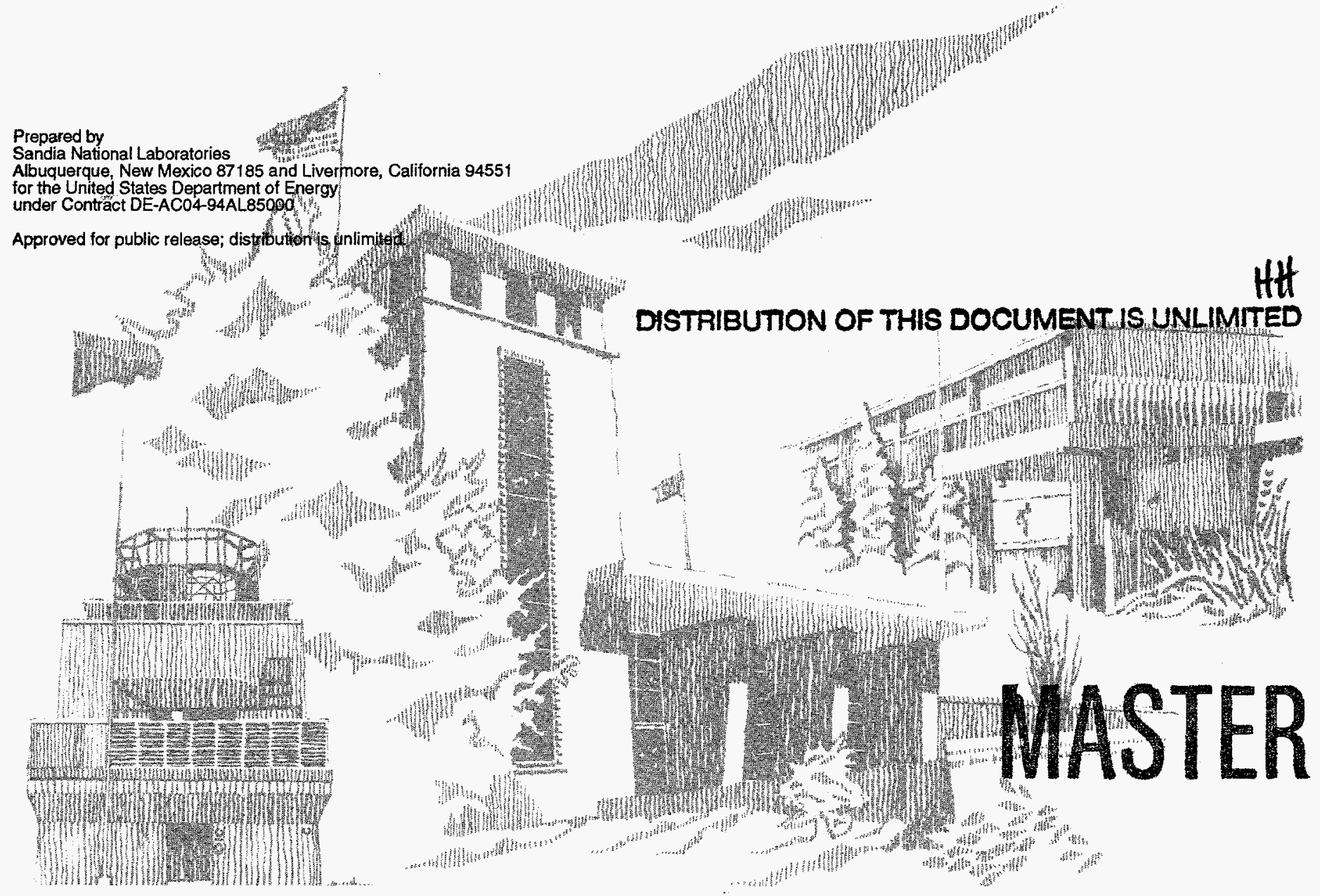


Issued by Sandia National Laboratories, operated for the United States Department of Energy by Sandia Corporation.

NOTICE: This report was prepared as an account of work sponsored by an agency of the United States Government. Neither the United States Government nor any agency thereof, nor any of their employees, nor any of the contractors, subcontractors, or their employees, makes any warranty, express or implied, or assumes any legal liability or responsibility for the accuracy, completeness, or usefulness of any information, apparatus, product, or process disclosed, or represents that its use would not infringe privately owned rights. Reference herein to any specific commercial product, process, or service by trade name, trademark, manufacturer, or otherwise, does not necessarily constitute or imply its endorsement, recommendation, or favoring by the United States Government, any agency thereof or any of their contractors or subconractors. The views and opinions expressed herein do not necessarily state or reflect those of the United States Government, any agency thereof or any of their contractors or subcontractors.

This report has been reproduced from the best available copy.

Available to DOE and DOE contractors from:

Office of Scientific and Technical Information

P. O. Box 62

Oak Ridge, TN 37831

Prices available from (615) 576-8401, FTS 626-8401

Available to the public from:

National Technical Information Service

U.S. Department of Commerce

5285 Port Royal Rd.

Springfield, VA 22161 


\section{DISCLAIMER}

This report was prepared as an account of work sponsored by an agency of the United States Government. Neither the United States Government nor any agency thereof, nor any of their employees, make any warranty, express or implied, or assumes any legal liability or responsibility for the accuracy, completeness; 'or usefulness of any information, apparatus, product, or process disclosed, or represents that its use would not infringe privately owned rights. Reference herein to any specific commercial product, process, or service by trade name, trademark, manufacturer, or otherwise does not necessarily constitute or imply its endorsement, recommendation, or favoring by the United States Government or any agency thereof. The views and opinions of authors expressed herein do not necessarily state or reflect those of the United States Government or any agency thereof. 


\section{DISCLAMMER}

Portions of this document may be illegible in electronic image products. Images are produced from the best available original document. 
SAND 95-8540

Unlimited Release

Printed May 1995

\title{
A CONTINUOUS EMISSIONS MONITOR FOR METALS: FIELD DEMONSTRATION OF A PROTOTYPE PROBE
}

\author{
William Flower, Larry Peng, Christine Woods, \\ Nina Bergan French, Ken Hencken, Howard Johnsen, \\ Ron Renzi, and Dan Trujillo \\ Sandia National Laboratories \\ Livermore, CA 94550
}

\begin{abstract}
Sandia National Laboratories conducted field tests of a prototype continuous emissions monitor for metals at Clemson University August 5-11, 1994, in cooperation with the joulemelter vitrification project at Clemson and Savannah River. The monitor is based on Laser Spark Spectroscopy, an established laboratory diagnostic technique that has been adapted for monitoring metal emissions from thermal waste treatment facilities. In the field tests described in this report, emissions were measured from a joule melter that was processing a surrogate waste-water treatment sludge from Oak Ridge. Data from this test provides the first insight into how emissions change (in real time) as operating parameters such as waste feed rate are changed. We detected all metals that were present above the estimated minimum detectability limits (in the parts-per-billion range for Clean Air Act metals), in addition to glass-making species such as calcium, boron, and silicon. This report summarizes the Clemson field tests, including design of the prototype probe, preparations leading up to the tests, the tests themselves, and analysis of results.
\end{abstract}




\section{ACKNOWLEDGMENTS}

This work was funded by the U.S. Department of Energy, Office of Technology Development.

We would like to thank the staff at Clemson University and Savannah River Mixed Waste Vitrification Project, who accommodated our tests and provided an excellent environment for operations. Special thanks go to (at Clemson): Tom Overcamp, David Bennert, John Harden, and Jim Resce; and (at Savannah River): John Plodinec, Donnie Helton, Denny Bickford, John Whitehouse, Connie Cicero, and Carol Jantzen. It was a pleasure to work with such competent teams.

We would also like to thank Buddy D'Allesandro and Ervin Myers of the Clemson University Vitrification Facility whose diligence, flexibility, and extra efforts were most important for completing these experiments.

At Sandia, the expert assistance of Lindsey Westbrook was indispensable in the preparation of this report and is gratefully appreciated. 


\section{CONTENTS}

\section{Page}

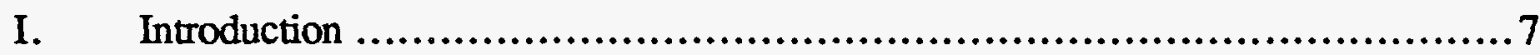

II. Laboratory Development .................................................... 8

III. Prototype Design .............................................................11

IV. Data Acquisition and Analysis Procedures …................................16

V. Field Experiments .......................................................... 18

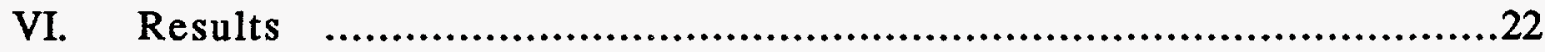

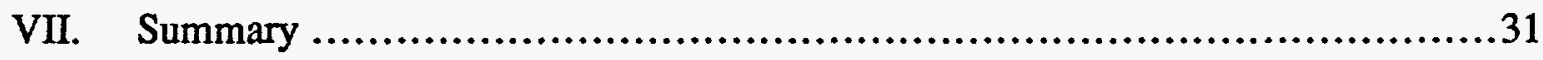

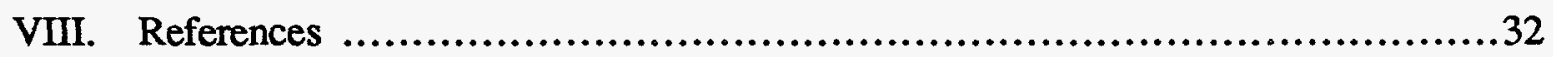

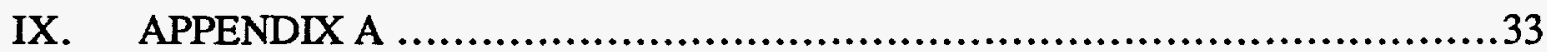




\section{TABLES}

No.

II.1 Minimum Detectable Concentrations Of The Eleven Metals Regulated Under

The Clean Air Act, As Measured Using Laboratory LASS System

V.1 Surrogate Waste: Concentrations Of Selected Metals In Waste Feed

V.2 Relative Manganese, Cadmium, Lead, And Iron Concentrations In The Five Different Waste Slurries Used In The Clemson Tests

\section{ILLUSTRATIONS}

Figure II.1 Schematic diagram of the laser-spark-spectroscopy system used for

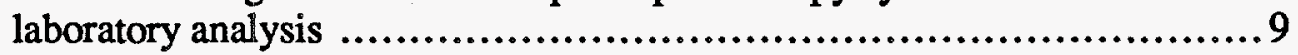

Figure III.1 Diagram of the prototype fieldable optical probe $\ldots \ldots \ldots \ldots \ldots \ldots \ldots \ldots \ldots \ldots . . . . . . . .13$

Figure III.2 Photograph of the prototype fieldable optical probe $\ldots \ldots \ldots \ldots \ldots \ldots \ldots \ldots \ldots . . . .14$

Figure III.3 Photograph of the two instrumentation modules for the fieldable multimetals CEM .................................................................. 15

Figure IV.1 The Data Acquisition front panel as launched from the Finder desktop .....17

Figure V.1 Photograph of the optical probe as mounted on the stack of the Stir Melter

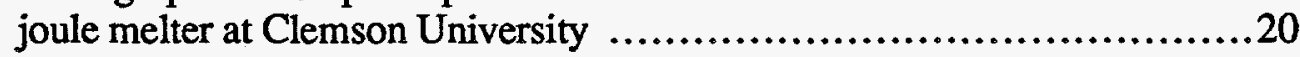

Figure VI.1 Measured optical emission from cadmium at $226.5 \mathrm{~nm}$....................24

Figure VI.2 Measured optical emission from manganese at $257.6 \mathrm{~nm}$................25

Figure VI.3 Measured optical emission from lead at $220.4 \mathrm{~nm}$......................26

Figure VI.4 Spark spectra acquired as waste feed ...................................29

Figure VI.5 Cadmium concentration during feedstream startup transient ................30 


\section{A CONTINUOUS EMISSIONS MONITOR FOR METALS: FIELD DEMONSTRATION OF A PROTOTYPE PROBE}

\section{INTRODUCTION}

\section{The Need for Continuous Emissions Monitoring}

The Department of Energy relies primarily on thermal treatment processes to treat its waste since DOE waste streams are so large, diverse, and threatening that it is not possible to rely solely on non-thermal processes. A major challenge in gaining approval for the necessary waste treatment plants is convincing the public and regulators that the effluent from the treatment process is free from toxic compounds. Metals, in particular, can be highly toxic even in small amounts and are among the most serious health risks of any emissions from thermal treatment facilities. Thus, the fate of metals in thermal treatment processes is a crucial concern to DOE, as well as to DoD and commercial waste processors.

The Clean Air Act specifically regulates eleven metals that are of primary concern as air toxins: antimony (Sb), arsenic (As), beryllium (Be), cadmium (Cd), chromium $(\mathrm{Cr})$, cobalt $(\mathrm{Co})$, lead $(\mathrm{Pb})$, mercury $(\mathrm{Hg})$, manganese $(\mathrm{Mn})$, nickel $(\mathrm{Ni})$, and selenium $(\mathrm{Se})$. Continuous monitoring of these metals in the effluent from thermal-treatment facilities could provide assurance that public health and safety is not endangered, but suitable monitors are not currently available. Present technologies for determining metal enissions rely on extractive sampling of the effluent followed by off-line laboratory analysis. This is a largely manual procedure that is costly, introduces sampling errors, and typically has turnaround times on the order of days or weeks, thereby preventing continuous assurance of environmental compliance. In addition to providing continuous assurance that a thermal treatment facility is always operating safely, continuous metal emissions data could be used to optimize processes in a way that would allow more waste to be treated at acceptable emission levels. These benefits will be valuable to DOE facilities that are currently operating as well as to those that are in the process of obtaining permits for waste-treatment operations.

\section{Advanced Techniques For Continuous Metal Emissions Monitoring}

The monitor developed in this project is based on an optical technique called $L A$ ser Spark Spectroscopy, also known as LASS. In this technique, a high-power pulsed laser is focused in the effluent stream. The high laser energy density in the focal region generates an optical breakdown, commonly called a laser spark or laser-induced plasma, in which particles and molecules are decomposed into excited atoms and ions. The variation of the intensity of light emitted by these excited species as a function of wavelength (the "spectral signature" of the emitting species) correlates directly with the type and quantity of netal present. An obvious advantage of a LASS-based continuous emissions monitor is the inherent ability of the technique to measure atomic species embedded in either particles, fine aerosols, or vapors in-situ in a stack. The LASS technology appears very promising for measuring metals in the effluent from hazardous waste treatment units, as well as for other applications, including monitoring metal emissions from munitions deactivation furnaces, fossil power plants, industrial furnaces and boilers, and industrial processes such as electroplating. 
Several other advanced technologies to measure metal emissions are now under development at other laboratories. Emissions monitors based on Inductively Coupled Plasma - Atomic Emission Spectroscopy (ICP/AES) ${ }^{1}$ and the Microwave Induced Plasma (MIP) Spectrometer ${ }^{2}$ also can provide continuous emissions measurements, while the HEST $^{3}$ (Hazardous Element Sampling Train) and the SpinCon ${ }^{4}$ technologies are not true continuous emissions monitors (hereafter referred to as CEMs) since they do not provide continuous data. The latter two techniques are based on analysis of extractive samples taken over a period of 30 minutes to 3 hours, but they differ from current sample-andanalyze techniques by virtue of the fact that automatic sample analysis is possible. Each of these advanced technologies (LASS, ICP/AES, MIP, HEST, or SpinCon) provides different relative advantages and disadvantages, but among these techniques, only LASS and MIP offer measurements that are both continuous and in-situ.

\section{Project Summary}

The overall objective of this project described here is to develop and demonstrate an instrument based on LAser Spark Spectroscopy (LASS) that will continuously monitor metal emissions in offgas from thermal treatment units. That is, we have started with a basic laboratory diagnostic technique and have worked to develop a field instrument based on that technique. In this effort, we have defined effluents of concern to DOE/EM waste treatment processes, and we have verified the validity of the basic LASS technique for measuring simulated effluent in the laboratory. In January, 1994, we began design and fabrication of a prototype field instrument, which was demonstrated at a DOE waste treatment field experiment in August, 1994. Based on results from this demonstration, we currently are designing an improved prototype monitor, which will be tested in the Spring of 1995.

\section{Objectives of Field Demonstration}

The fundamental objective of the field tests described in this report is to demonstrate the utility of the laser-spark technique as a continuous monitor of metal emissions from thermal waste-treatment processes. The tests were designed to evaluate the ability of the monitor to operate continuously and reliably in a field environment while providing real-time measurements of metal emissions from an actual waste treatment unit. Our technical goals include demonstrating: (a) that regulated metals can be measured at concentrations comparable to regulated limits; (b) that we can measure the effect of system operating parameters on metal emission rates; and (c) that we can follow transient variations in metal concentrations that result from temporal variations in operating parameters or flow conditions.

\section{LABORATORY DEVELOPMENT}

The laboratory LASS system that we have developed (Figure II.1) uses a high-power, Qswitched, frequency-doubled, Nd:YAG laser beam (nominally $300 \mathrm{~mJ} / \mathrm{pulse}$ ), which is

focused into a simulated effluent flow. Because of the high particle number density in 


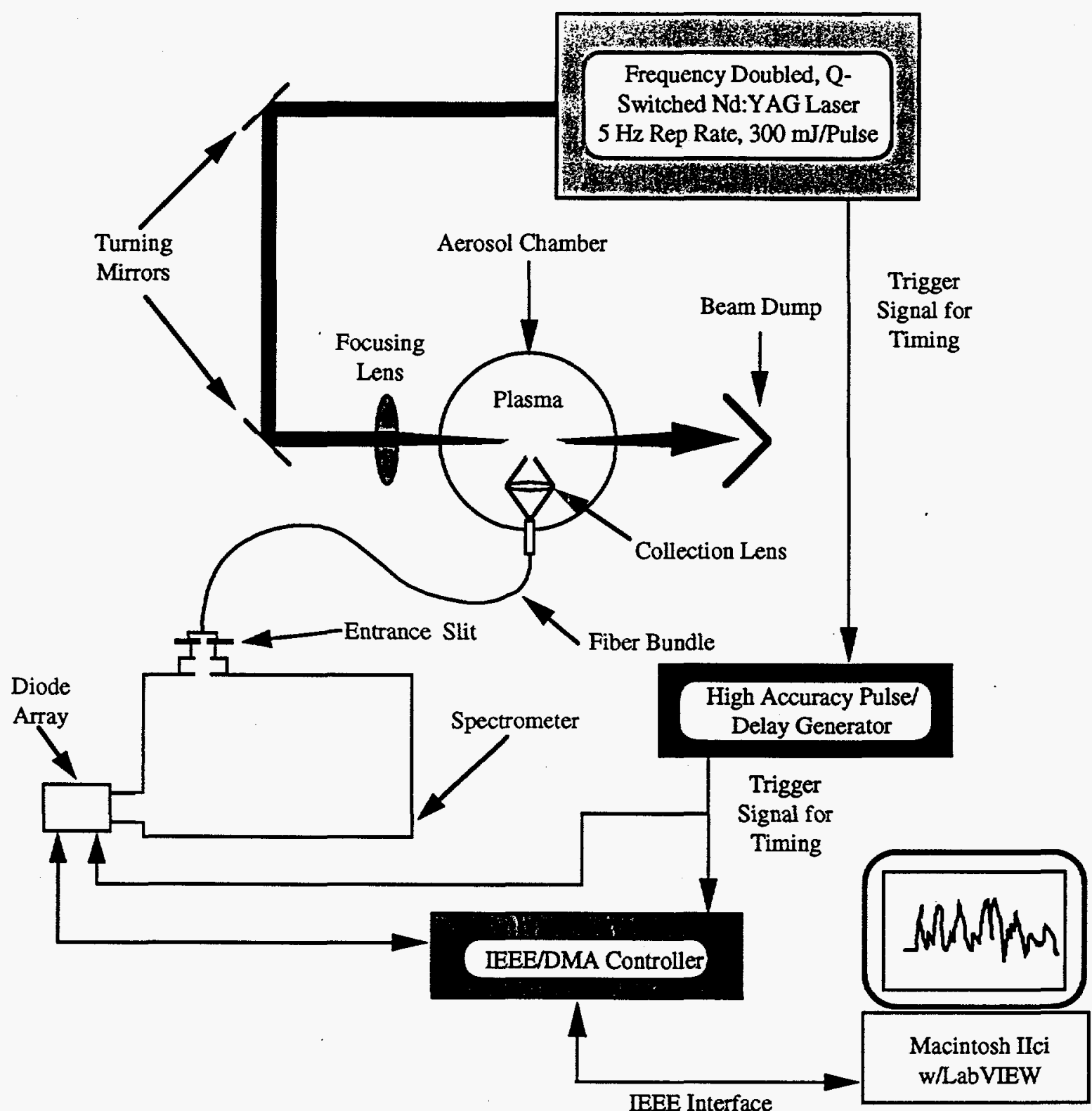

Figure II.1 Schematic diagram of the laser-spark-spectroscopy system used for laboratory analysis. 
the simulated effluent, the focal volume contains multiple particles at any time. Hence, the laser can be pulsed at a fixed repetition rate (up to $5 \mathrm{~Hz}$ in these experiments), and an ensemble of particles is measured for each laser pulse. Optical emission from the laserinduced plasma is focused onto the face of a fiber-optic bundle, which transmits the light to a grating spectrometer. The spectrometer entrance slit was set to provide spectral resolution on the order of $0.1 \mathrm{~nm}$. A linear photodiode array (time-gated to the laser pulse) measures the distribution of light intensity as a function of wavelength. A more comprehensive description of the laboratory LASS system is included in a previous paper. 5

In the laboratory, size distributions and metal content of typical effluent were simulated using a commercial nebulizer to disperse a fine mist of a metal solution. For most of the Clean Air Act metals, we used commercially prepared 1000-ppm solutions of the individual metals in dilute acid. For a few of the metals, we prepared $1 \%$ aqueous solutions of metal salts in our own laboratory. The nebulizer was enclosed by an exhaust chamber to prevent contamination of the room environment. The particle size distribution of the nebulizer flow was characterized using a commercial particle sizer/velocimeter probe. Particles were $0.3-15 \mu \mathrm{m}$ in diameter at a cumulative number density of $3 \times 10^{5}$ particles $/ \mathrm{cm}^{3}$.

In a few experiments, a vibrating-orifice aerosol generator was used to produce monodisperse metal aerosols of controllable size. Laboratory investigation did not reveal a significant difference in atomic emission per metal atom between 10- $\mu$ m-diameter and 20 $\mu \mathrm{m}$-diameter droplets. This result indicates that the laser energy used here was great enough to completely ionize droplets as large as $20 \mu \mathrm{m}$, which are much larger than we expect to see downstream of air-pollution-control equipment in an actual stack flow.

For laboratory LASS measurements of simulated effluent aerosols, we positioned the nebulizer below the laser focal volume and selected operating conditions that produced a fine mist with the desired metal mass concentration in the laser focal region. All laser pulses induced laser breakdown of the mist. For each of the Clean Air Act metals, atomic emission lines were clearly evident in spark-emission spectra measured for single laser shots, but for many of these metals the signal-to-noise ratio for a single-shot spectrum was only fair, and there was significant variability between spectra obtained from different laser pulses. Averaging the spectra over multiple laser pulses yielded spectra with improved signal-to-noise ratios that were very reproducible.

For each of the eleven Clean Air Act metals, we scanned the laser-spark emission spectrum to determine the strongest emission features for individual metals and to identify potential interferences between emission from different species. Single-metal survey spectra displayed one or more distinct optical emission lines for each of the metals that was examined. Individual lines were identified using standard tabulations of atomic emission spectra. Few direct interferences were observed between emission from different metals, and, in the cases where more than one metal emitted at a particular wavelength, there was a suitable second or third emission line that was relatively interference-free.

We verified linearity of LASS measurements with metal concentration in the case of chromium by examining aerosols generated using solutions containing different chromium concentrations. Measurements of LASS emission from an aerosol of pure water were used to determine the limiting background intensity as a function of wavelength, which we subtracted from the total emission signal to determine chromium emission spectra. Both peak and integrated chromium line intensities were proportional to chromium concentration to within $10-20 \%$ as concentration varied by two orders of magnitude. 
TABLE II.1

Minimum Detectable Concentrations Of The Eleven Metals Regulated Under the Clean Air Act, As Measured Using Laboratory LASS System

\begin{tabular}{|c|c|}
\hline Element & $\begin{array}{c}\text { Minimum Detectable } \\
\text { Concentration (ppb) }\end{array}$ \\
\hline $\mathrm{Be}$ & $<0.1$ \\
\hline $\mathrm{Mn}$ & 0.25 \\
\hline $\mathrm{Cr}$ & 1 \\
\hline $\mathrm{Cd}$ & 2 \\
\hline $\mathrm{Co}$ & 2 \\
\hline $\mathrm{As}$ & 15 \\
\hline $\mathrm{Hg}$ & 15 \\
\hline $\mathrm{Sb}$ & 35 \\
\hline $\mathrm{Ni}$ & 40 \\
\hline $\mathrm{Se}$ & 160 \\
\hline $\mathrm{Pb}$ & 250 \\
\hline
\end{tabular}

Ultimately, the ability to measure line emission from an individual metal is limited by whether the spectral lines can be distinguished from noise in the underlying continuum background. We have chosen to define the minimum detectable concentration for each metal as the metal concentration for which the ratio of the peak line intensity to the noise in the underlying background has a value of 3 . For each of the eleven Clean Air Act metals we measured the peak intensity of the strongest emission line for a known reference concentration and calculated the ratio of this signal to the statistical noise in the continuum background. Minimum detectable concentrations were then calculated from these reference signal-to-noise ratios, assuming that peak line intensities are linear with metal concentration. Minimum detectable concentrations range from better than $0.1 \mu \mathrm{g}$ per standard cubic meter $(\mu \mathrm{g} / \mathrm{scm})$ for beryllium, the most detectable metal, to about 250 $\mu \mathrm{g} / \mathrm{scm}$ for lead, the least detectable $(1 \mu \mathrm{g} / \mathrm{scm}$ is essentially equivalent to 1 part per: billion, $\mathrm{ppb}$, on a mass-to-mass basis). Table II.1 lists the minimum detectable concentrations determined in the laboratory for all of the Clean Air Act metals.

\section{PROTOTYPE DESIGN}

While the laboratory experiments described above are useful to prove the feasibility of a LASS-based continuous emissions monitor and to define CEM parameters, clearly the laboratory LASS system is not suitable for field use. The fieldable CEM must be compact, rugged, easily transported, and easily installed at a waste treatment facility. In addition, the fieldable CEM should require minimal optical access to the stack, since suitable ports may be few and not easily changed. The distance from the probe hardware to the measurement volume should be adjustable, the device should require only minimal optical alignment, and any required alignment must be simply performed in the field. Most importantly, sensitivity to target species must be sufficient to measure actual concentrations in the effluent. 
In response to these requirements, we have designed and constructed a fieldable prototype metal-emissions monitor that consists of four basic pieces: (1) an optical probe, which contains a pulsed Nd:YAG laser plus focusing and collection optics; (2) ruggedized instrumentation racks that contain a spectrometer, detector, control instrumentation, and the laser power supply; and (3) a personal computer for data acquisition and control.

\section{Optical Probe}

The configuration of the optical probe assembly is shown in Figure III.1. The frequencydoubled ( $532 \mathrm{~nm}$ ), Q-switched, laser output is expanded and collimated by a pair of lenses, passes through a hole in a mirror that is mounted at 45 degrees relative to the beam, and then is focused in the effluent stream by a plano-convex lens. The laser-focusing lens also serves to collect and collimate a portion of the optical emission from the laser-induced breakdown. Most of this collected emission reflects off the mirror through which the incident laser beam originally passed, effectively separating the collected plasma emission from the counter-propagating laser beam. This emission then reflects off a second mirror and is focused on the tip of a 10-meter-long fiber-optic bundle, which transmits the plasma emission to the instrumentation-rack-mounted spectrometer and detector. Attenuation of light in the fiber results in reduced detection sensitivity for the prototype CEM than was achieved using the laboratory bench-top system.

Not shown in Figure III.1 are two additional components: a detector to measure the laser power, and a mercury discharge lamp to provide a wavelength reference for calibration. The completed prototype optical probe is shown in Figure III.2.

\section{Instrumentation Modules}

Two separate assemblies house the spectrometer, detector, electronics, and power supplies. Individual instruments are mounted in steel-framed instrument racks that are connected by rubber shock-absorbing mounts to rugged, injection-molded-plastic, containment shells. The instrumentation modules are sufficiently shock-protective that a separate external shipping container is not required.

The larger of the two instrument racks is $1.4-\mathrm{m}$ high by $0.75-\mathrm{m}$ wide (outside shell dimension) and contains the laser power meter readout, a $0.275-\mathrm{m}$ grating spectrometer combined with a linear photodiode array detector (1024 elements), control and gategenerating electronics for the photodiode array, and an uninterruptable power supply. The end of the fiber-optic bundle that delivers plasma emission is mounted directly to the adjustable spectrometer entrance slit.

The second instrumentation rack $(0.9-\mathrm{m}$ by $0.75-\mathrm{m})$ contains the laser power supply. An umbilical bundle containing electrical and cooling-water lines connects the power supply to the laser head in the optical probe assembly.

Figure III. 3 is a photograph of the two instrumentation modules. 

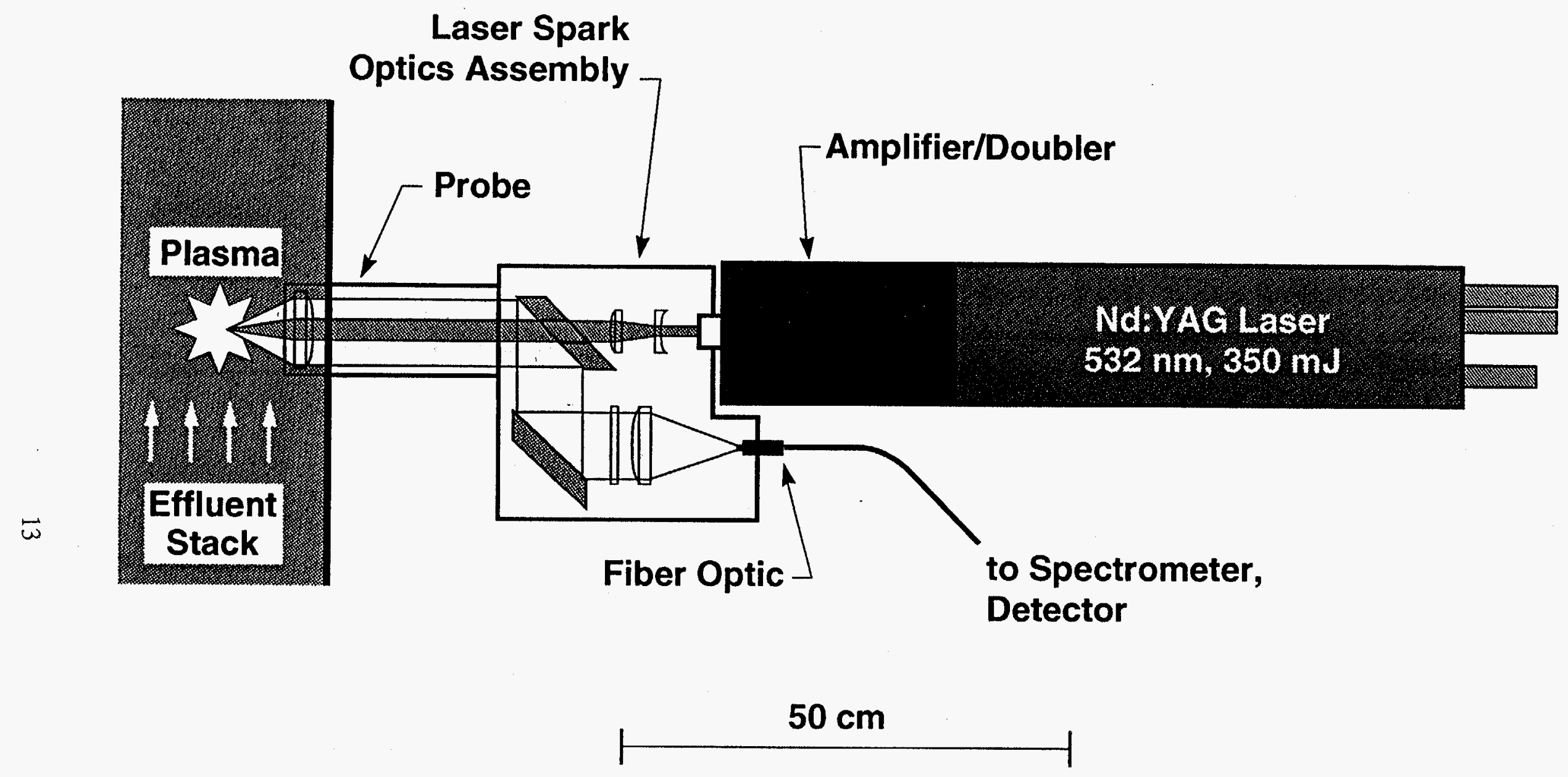


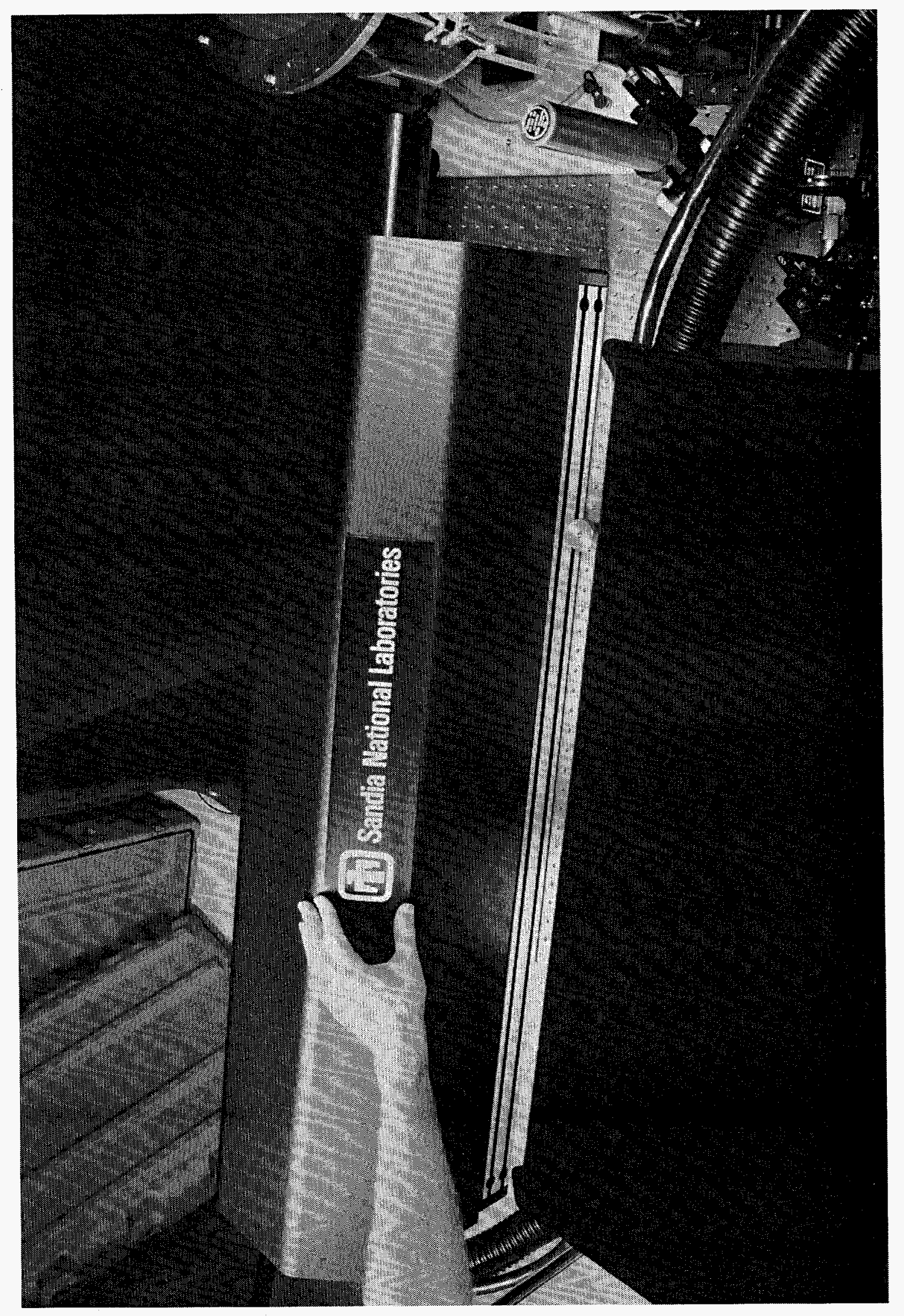

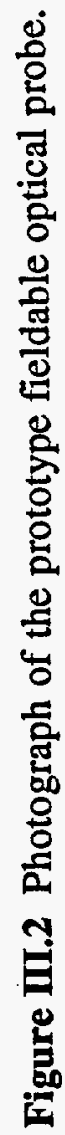




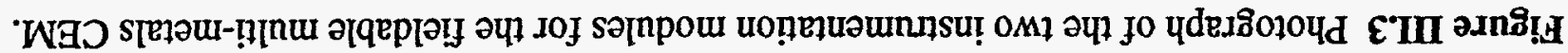

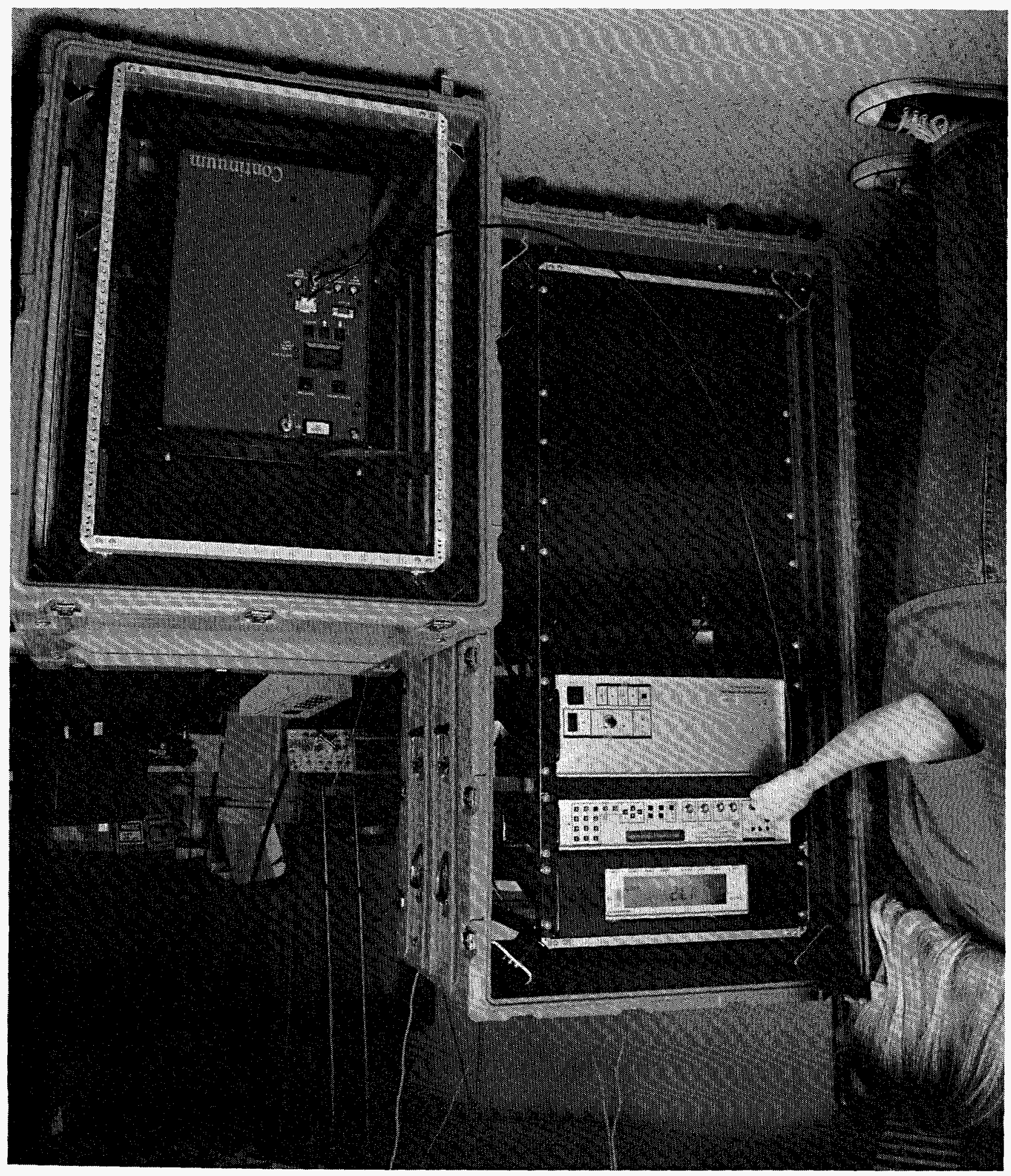




\section{Data-Acquisition Computer}

A Macintosh IIci computer is used for data acquisition and analysis. For the initial field test, the computer was not packaged in an integrated assembly. The computer and monitor will be rack mounted in future designs.

\section{External connections}

The only electrical connections required for the complete monitor system are a 110-V line for the uninterruptable power supply (UPS) and a 220-V, single-phase line for the laser power supply. All other electrical devices (including the computer and peripherals) are plugged into the UPS. A compressed-gas cylinder supplies a small flow of nitrogen to purge the face of the photodiode array. A laboratory water tap provides cooling water for the photodiode array thermolectric cooler. (A recirculating water cooler can be used alternatively at sites where tap water is not available.)

\section{DATA ACQUISITION AND ANALYSIS PROCEDURES}

The CEM software is composed of two major program components (one for data acquisition and the other for data analysis) that function as an integrated unit. These programs share common modules for transferring data between them. In addition, the programs contain capabilities for generating, editing, plotting, and printing data files and for exporting data to third-party software packages. The programs were written using the LabVIEW development environment (National Instruments Corporation) on an Apple Macintosh II series computer and can been used without modification on any 680X0-based Macintosh with at least one Nu-Bus expansion slot.

The software design reflects several major objectives. First, the user has interactive control and visual feedback. Access to various experimental parameters should be easily available, yet unobstrusive. This allows for faster optimization of a given laboratory configuration since the user can observe any changes in the signal while data acquisition is in progress. Second, the program puts the acquired data into a common structure that can be used by other software components. Doing this minimizes software overhead and simplifies the extraction of information from the data. Third, the architecture supports multiple communication protocols. This is required to support the different types of instruments that acquire data or monitor laser-probe status. Finally, the program architecture should be sufficiently open so that the program can be ported to similar applications with minimal modification.

\section{Data Acquisition}

For the first field test, data acquisition was performed independently of data analysis. Scanning and averaging parameters, as well as some instrument settings, are user-set from the data acquisition control panel, shown in Figure IV.1. Spectra can be acquired as a single scan of the diode array, or as an average of multiple diode array scans. Acquired diode-array spectra are averaged and displayed on the control panel in real time. The user then chooses whether to save the data to a permanent file and/or send the data to the: analysis program. Future versions of the software will be completely automated. 


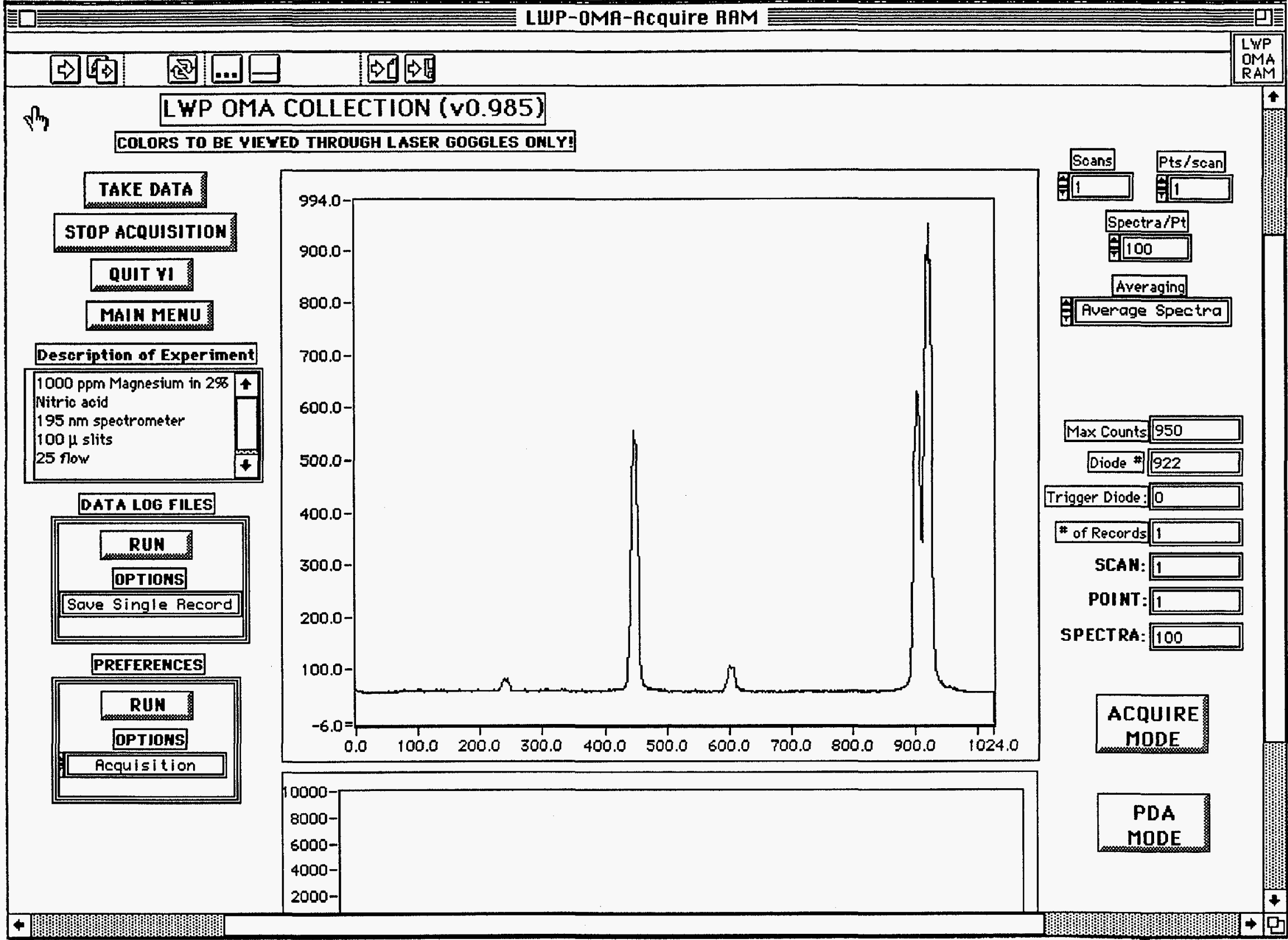

Figure IV.1 The Data Acquisition front panel as launched from the Finder desktop. 


\section{Analysis Procedure}

We determined metal concentrations in the stack at Clemson by comparing the field (stack) spectra to laboratory reference spectra for aerosols with known metal concentrations. The laboratory reference spectra were obtained beforehand (at Sandia) for each metal that we expected to encounter in the field test. Field spectra and reference spectra were first preprocessed to determine the wavelength scale and to subtract the continuum "background" underlying the structured line-emission spectra. Both sets of measured spectra were linked to a common wavelength scale through the use of standard-lamp emission spectra that were measured both in the laboratory (at the time of the reference measurements) and in the field. We subtracted the backgrounds of the two sets of spectra by one of two methods: we either subtracted a scaled spectrum for water from the measured metal spectra; or we simply subtracted a constant offset value from the measured metal spectra.

We evaluated several multivariate techniques, including Principle Component Regression and Partial Least Squares, to model the relationship between the unknown metal spectra and the reference metal spectra; however, we found that our system was sufficiently linear to be described accurately by Classical Least-Squares. Basically, for each metal, we used MATLAB (from The MathWorks, Inc.) to solve for the coefficient relating the reference and unknown spectra in the equation:

$$
\text { (Reference Spectrum) } \times \text { coefficient }=(\text { Unknown Spectrum })
$$

subject to the constraint that the sum of the squares of the residual error at each wavelength was minimized. The coefficient determined in this way is the ratio of the concentration of the metal in the unknown sample to its known concentration in the reference sample. In order to simplify the analysis and minimize interfering information, we analyzed the measurements to determine only one metal at a time.

\section{FIELD EXPERIMENTS}

Measurements at Clemson were made in the effluent stream from a pilot-scale joule-meltertype vitrification unit produced by Stir Melter, Inc. Exact technical details of the joule melter and operating conditions are proprietary and protected by non-disclosure agreements. Technical inquiries regarding this facility should be directed to Clemson University or to Stir Melter. This section summarizes the experiments that were conducted at Clemson and preparations made specifically for these experiments.

\section{Pre-Test Preparations at Sandia}

The single-metal reference spectra used in the quantitative analysis of field measurements were obtained at Sandia prior to departure for Clemson. In the laboratory, laser-spark spectra were measured for an aerosol flow containing a known metal concentration of $10 \mathrm{ppm}$. Measurements were repeated for each of the eleven Clean Air Act metals listed in 
Table II. 1 and for seven additional non-regulated species anticipated in the Clemson effluent: aluminum, boron, calcium, iron, silicon, silver, and magnesium. The same prototype CEM hardware and operating parameters were used for these reference measurements as for the field tests. Thus, the reference measurements served to calibrate system response for the subsequent field measurements.

\section{Transport of the Prototype CEM}

A large (1.9-m x 0.66-m $\times 0.53-\mathrm{m})$ wooden shipping crate was constructed to protect the optical-probe assembly during transport. Two additional shipping crates were constructed to house the data-acquisition computer, tools, spare parts, and documentation. The prototype's two ruggedized instrument racks were strapped to wooden pallets for shipping. No additional preparations were required for these units since the racks are designed to vibrationally isolate the instruments they contain. The total weight of the parcels shipped to Clemson was approximately $750 \mathrm{~kg}$, less than half of which was the prototype itself. All of the equipment was shipped to Clemson by overnight air freight and was ready to be installed at Clemson the next day.

\section{Pre-Test Preparations at Clemson}

Only a few advance facility modifications were required at Clemson to accommodate the prototype LASS CEM. Prior to the tests, Sandia fabricated and shipped to Clemson a new stainless-steel exhaust-stack section that provided optical access to the effluent. This test section is $1.1-\mathrm{m}$-long with an inside diameter of $5.3 \mathrm{~cm}$. A pair of opposing window ports are located $0.6 \mathrm{~m}$ above the joule-melter exit. This section is interchangeable with the previously existing section and was installed by Clemson personnel prior to the tests. Clemson staff also constructed a platform to support the LASS CEM optical probe assembly at the level of the optical port, approximately 2 meters above floor level.

Upon arrival of the prototype CEM from Sandia, Sandia and Clemson personnel spent portions of 2 days installing the probe at Clemson. The process included uncrating the instruments, checking for damage, establishing electrical and water connections, and performing minor realignment of the optical head. (For comparison, it took just 2 hours to uncrate the system and re-establish operations upon return to Sandia, where electrical and water connections were already well defined.) Figure V.1 shows the optical probe unit installed on the effluent stack at the Clemson University Vitrification Facility.

\section{Description of Field Tests}

Appendix A contains a listing of the major tasks that constituted the field tests series. Of the nine major tasks, the first seven encompass the tests at Clemson from uncrating of the equipment on August 3 until the last measurements on August 11. Task 8, chemometric analysis of the atomic emission spectra to obtain quantitative concentration measurements, was performed after completion of the test series, and Task 9, the collection of extractive emission samples for chemical analysis, was performed at Clemson prior to this test series. Also included in Appendix A is the sequential checklist used for field test operations. 


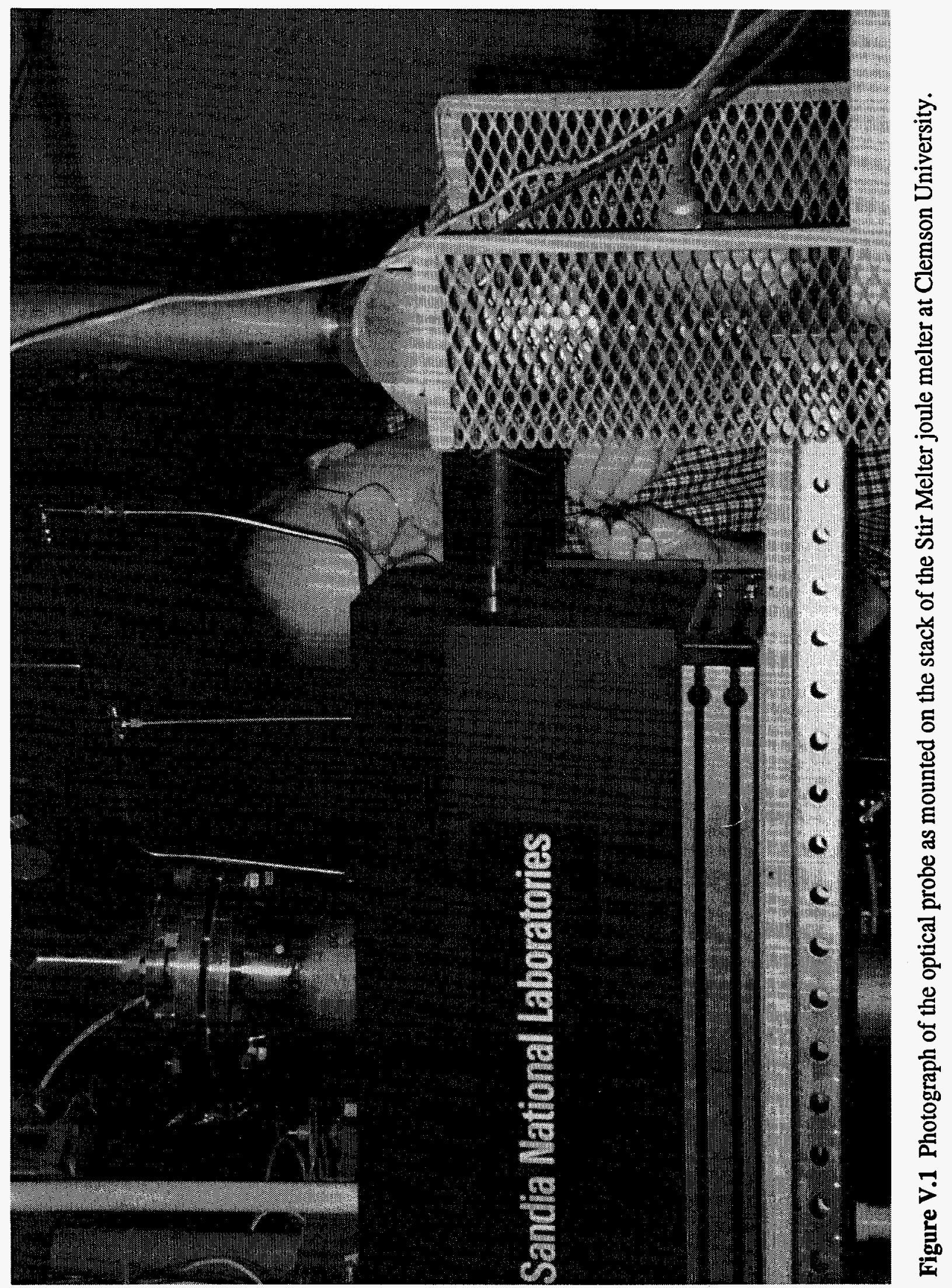


The nominal waste input stream to the joule melter was OR2-2, a surrogate Oak Ridge West-End Treatment Facility waste slurry. This waste contained four of the eleven metals regulated under the Clean Air Act (cadmium, chromium, lead, and nickel), each with concentration less than $0.03 \%$ (by mass) of the wet slurry. Mass concentrations of selected metals in the wet OR2-2 waste are listed in Table V.1.

TABLE V.1

OR2-2 Surrogate Waste: Concentrations Of Selected Metals In Waste Feed

\begin{tabular}{|c|c|}
\hline Species & Concentration \\
\hline $\mathrm{Al}$ & $0.635 \%$ \\
\hline $\mathrm{Ba}$ & $0.0156 \%$ \\
\hline $\mathrm{Ca}$ & $4.37 \%$ \\
\hline $\mathrm{Cd}$ & $0.000876 \%$ \\
\hline $\mathrm{Ce}$ & $0.0201 \%$ \\
\hline $\mathrm{Cr}$ & $0.0112 \%$ \\
\hline $\mathrm{Cu}$ & $0.0199 \%$ \\
\hline $\mathrm{Fe}$ & $0.201 \%$ \\
\hline $\mathrm{Li}$ & $0.952 \%$ \\
\hline $\mathrm{Mg}$ & $0.156 \%$ \\
\hline $\mathrm{Na}$ & $0.233 \%$ \\
\hline $\mathrm{Ni}$ & $0.0292 \%$ \\
\hline $\mathrm{Pb}$ & $0.00463 \%$ \\
\hline
\end{tabular}

To ensure that regulated metals would be in the effluent at reasonable concentrations, we also prepared four "spiked" waste slurries containing higher concentrations of several of the CAA metals. Three of these were prepared by adding varying amounts of Manganese dichloride, Cadmium acetate, and Lead acetate to the base OR2-2 waste; in the fourth spiked waste, Iron (III) oxide was also added so that we could analyze the regulated metals in the presence of spectral interferences from atomic iron. Table V.2 summarizes the manganese, cadmium, lead, and iron concentrations in the five waste slurries (OR2-2 and four spiked mixtures). Measurements were also made when the input waste feedstream was replaced by a stream of pure water and when no waste at all was being added to the joule melter. The flowrate for all feedstreams was set at $45 \mathrm{ml} / \mathrm{min}$, although large intermittent fluctuations occurred because of difficulties in smoothly pumping the nonNewtonian waste slurry.

TABLE V.2

Relative Manganese, Cadmium, Lead, And Iron Concentrations In The Five Different Waste Slurries Used In The Clemson Tests

\begin{tabular}{|c|c|c|c|c|}
\hline Mixture & Mn & Cd & Pb & Fe \\
\hline OR2-2 & $0 \%$ & $0.00088 \%$ & $0.0046 \%$ & $0.2 \%$ \\
\hline Spiked OR2-2 & $0.050 \%$ & $0.00088 \%$ & $0.0046 \%$ & $0.2 \%$ \\
\hline Spiked OR2-2 & $0.20 \%$ & $0.20 \%$ & $1.0 \%$ & $0.2 \%$ \\
\hline Spiked OR2-2 & $0.40 \%$ & $0.40 \%$ & $2.0 \%$ & $0.2 \%$ \\
\hline Spiked OR2-2 & $0.40 \%$ & $0.40 \%$ & $2.0 \%$ & $4.4 \%$ \\
\hline
\end{tabular}




\section{CEM Operating Parameters}

The laser flashlamp was pumped at a rate of $5.3 \mathrm{~Hz}$, and the cavity Q-switch was triggered for every third flashlamp firing, so that pulsed laser output was obtained at a $1.8-\mathrm{Hz}$ pulse repetition rate. The output was always frequency doubled. The measured average laser power at nominal operating conditions was typically $0.55 \mathrm{~W}$, implying single-pulse energy of $300 \mathrm{~mJ}$. In a few tests, the flashlamp energy was decreased in order to reduce the pulse energy.

For each laser pulse, the gated diode array measured spark emission in a selected spectral region. The data acquisition program reads the array output for each pulse, but for most tests we chose not to store the spectra from the individual laser shots; instead, emission measurements were typically averaged over 100 consecutive laser pulses (in a one-minute period) in order to enhance the signal-to-noise ratio and, hence, reduce the minimum detectable metal concentration. Operation in the averaging mode also speeds data acquisition and reduces the required disk storage space.

\section{CEM Field Performance}

The monitor performed reliably with no CEM system failures throughout the entire sevenworking-day period during which the tests were conducted. Early in the test series, the CEM ceased to detect plasma emission even though strong laser sparks were still observed. It was found that the test-section window had become nearly opaque due to a coating on the inside surface. The window was removed, and the remainder of the tests were successfully conducted with no window in this aperture. (At this time the CEM was loosely mated to the stack, so that the negative pressure of the stack flow served to induce a slight purge flow over the focusing lens. The lens remained clean for the remainder of the tests, except for one irregular event when liquid reached this location, requiring the lens to be removed and cleaned.)

The laser frequency-doubling crystal periodically required slight realignment to maintain stable laser power. We believe that the drift in alignment probably resulted from variations in the temperature of the probe surroundings. Realignment was rarely necessary in the afternoon after the building temperature had stabilized.

\section{RESULTS}

\section{General Observations}

When spiked wastes containing additional quantities of cadmium, manganese, and lead ( $0.05 \%$ to $2.0 \%$ by mass, as indicated in Table V.2) were added to the joule melter, laserinduced spark emission from these species was readily observed in the effluent. Spectral lines for each of the spiked metal species were identified and analyzed using the procedure described in Section IV. The base OR2-2 surrogate waste contained such low concentrations of regulated metals that we did not detect these metals. However, several glass-making species were measured in the effluent, including aluminum, magnesium, calcium, silicon, and boron. 
The intensity of individual spectral lines varied significantly from one laser pulse to the next, even when the nominal operating conditions were held fixed. The standard deviation in the cadmium concentrations derived from sequential individual laser pulses was typically $50 \%$ to $112 \%$ of the mean of the individual concentration measurements. This behavior suggests either that there were large variations in the sample being measured between different laser pulses, or that the response of the CEM to identical samples varied significantly from one pulse to the next. At this time, we cannot absolutely eliminate the latter explanation. However, the former explanation (change in sample conditions) is believed to contribute significantly to shot-to-shot variations for two different reasons: the particle number density is very low, causing significant statistical variations in the number of particles (and, hence, the quantity of metal) in the probe volume at any instant in time; and the interaction of the waste feedstream with the surface of the glass melt is a very unsteady process that could cause significant fluctuations in mean emission rates.

\section{Measurements Of Clean Air Act Metals}

Prior to the Clemson tests, we were concerned whether optical emission from interfering species would overwhelm spectra of the Clean Air Act metals, preventing accurate measurements of metal concentrations. Iron, in particular, is a major component of the OR2-2 waste that contributed numerous strong emission lines in spectral regions that were analyzed to determine concentrations of regulated metals. However, we found that manganese, lead, and cadmium (the three Clean Air Act metals that we targeted in our analysis) could be readily measured in spite of interference from iron, even when the iron concentration in the waste feed was increased to as much as 20 times its normal value in the OR2-2 waste.

Figure VI.1 shows a typical measured spark-emission spectrum for a well isolated cadmium line at $226.5 \mathrm{~nm}$. The solid line and circles represent measurements in the joulemelter effluent, while the dashed line is the best fit of the cadmium reference spectrum to the joule-melter measurements. Each spectrum is an average over 100 laser pulses, and the continuum "background" emission has been subtracted from each. This fit indicates that the cadmium concentration in the effluent during these measurements was $7 \mathrm{ppm}$. Based on the excellent signal-to-noise ratio and the good fit to the reference spectrum, we would expect that measurements at much lower cadmium concentrations should be possible. Indeed, for other test conditions at Clemson, we measured cadmium as low as $4 \mathrm{ppb}$, better than a factor of a thousand lower than the measurements of Figure VI.1.

We normally measured manganese by fitting the emission line at $257.6 \mathrm{~nm}$ to the reference spectrum at this wavelength. Figure VI.2 shows a typical measurement of the manganese spark spectrum in the joule-melter effluent. For this measurement, the waste feedstream contained $0.05 \% \mathrm{Mn}$, and analysis of the spectrum indicates that the manganese concentration in the effluent was $0.07 \mathrm{ppm}$. For other test conditions, manganese was measured at actual concentrations as low as $0.014 \mathrm{ppm}(14 \mathrm{ppb})$, and we estimate that manganese should be measurable in the effluent at concentrations lower than $1 \mathrm{ppb}$.

Although lead is the least detectable Clean Air Act metal for the laser-spark probe (Table II.1), we could, in fact, measure lead in the joule-melter effluent when lead-spiked waste was being processed. Figure VI.3 shows a typical lead spectrum for a case in which the waste feedstream contained $2 \%$ lead. Analysis of this spectrum indicates that the lead 


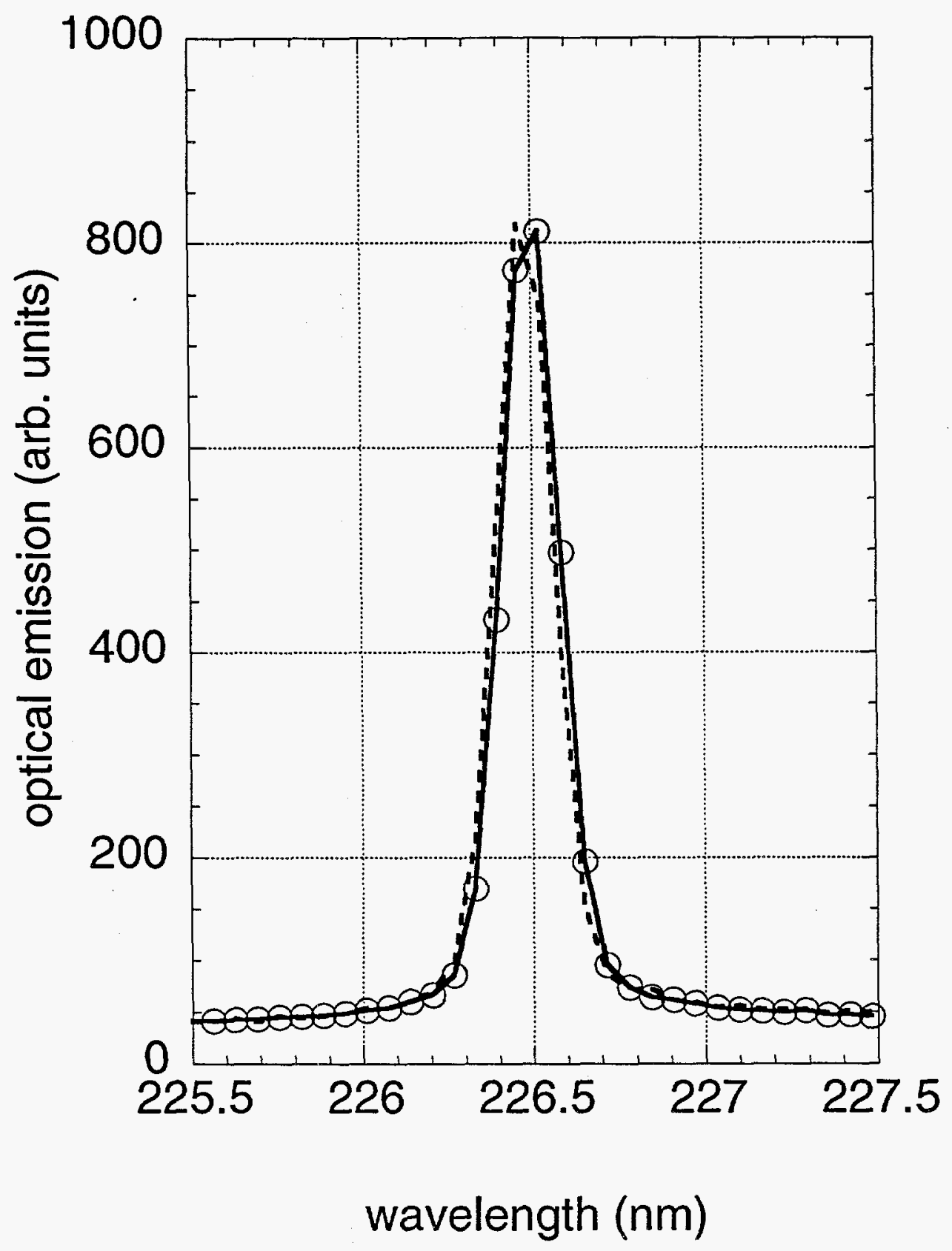

Figure VI.1 Measured optical emission from cadmium at $226.5 \mathrm{~nm}$. The solid line and circles represent field measurements in the joule-melter effluent, while the dashed line is the best fit of the cadmium laboratory reference spectrum to the field measurements. Each spectrum is an average over 100 laser pulses, and the continuum "background" emission has been subtracted from each. This fit indicates that the cadmium concentration in the effluent during these measurements was $7 \mathrm{ppm}$. 


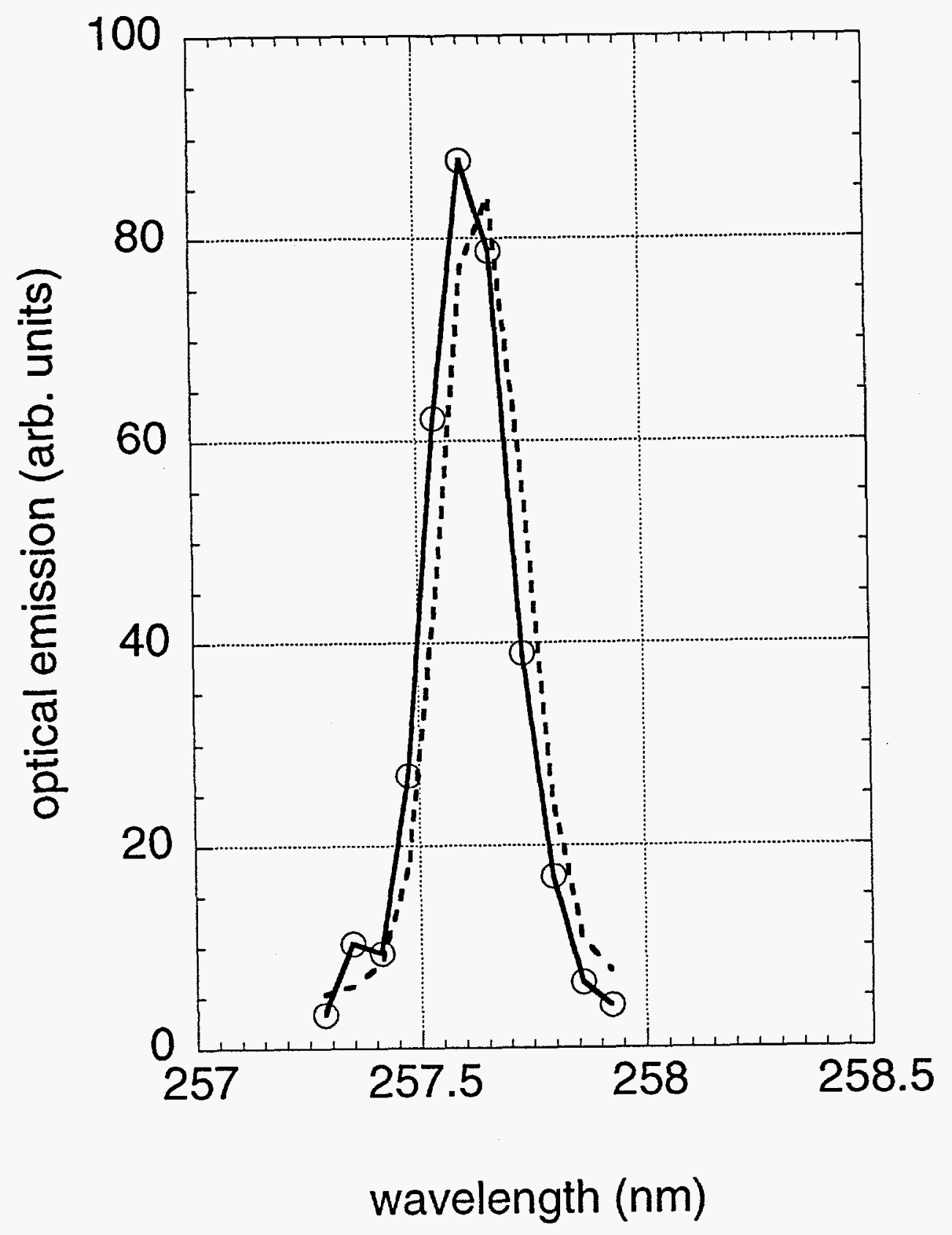

Figure VI.2 Measured optical emission from manganese at $257.6 \mathrm{~nm}$. The solid line and circles represent field measurements in the joule-melter effluent, while the dashed line is the best fit of the manganese laboratory reference spectrum to the field measurements. Each spectrum is an average over 100 laser pulses, and the continuum "background" emission has been subtracted from each. The indicated manganese concentration in the effluent for these measurements is $0.07 \mathrm{ppm}$. 


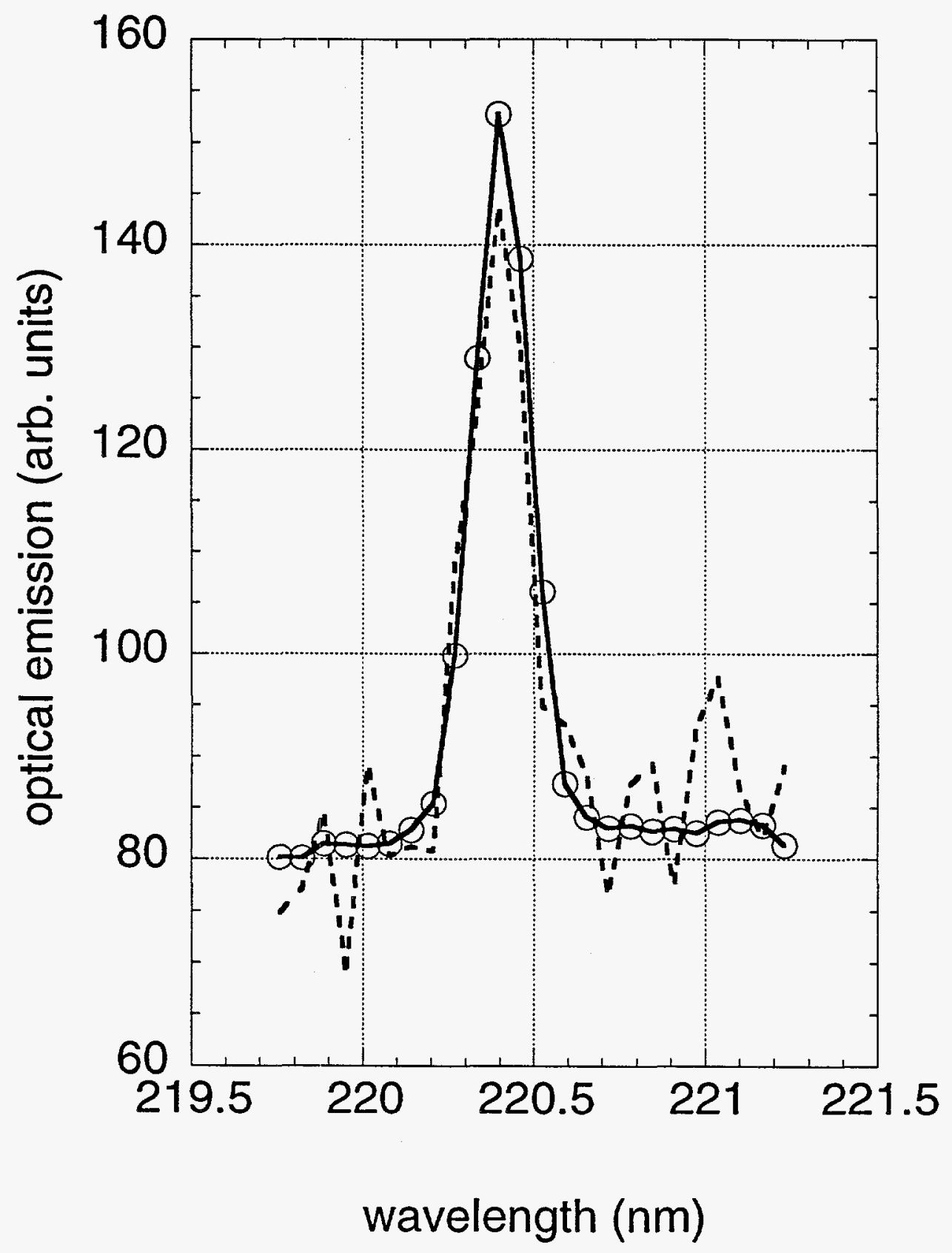

Figure VI.3 Measured optical emission from lead at $220.4 \mathrm{~nm}$. The solid line and circles represent field measurements in the joule-melter effluent, while the dashed line is the best fit of the lead laboratory reference spectrum to the field measurements. Each spectrum is an average over 100 laser pulses. The indicated lead concentration in the effluent for these measurements is $35 \mathrm{ppm}$. 
concentration in the effluent was $35 \mathrm{ppm}$. We measured lead concentrations as low as 2 ppm for other test conditions, and we estimate that lead concentrations as low as $1 \mathrm{ppm}$ should be measurable.

Table VI.1 summarizes the minimum concentrations measured for cadmium, manganese, and lead in the joule-melter effluent. Also listed here are our estimates of the minimum concentration of each of these three metals that should be measurable using the prototype CEM exactly as it was used in these tests. Estimates are based on the signal-to-noise ratios observed in the Clemson field measurements and on how well the reference spectra fit the field measurements. The minimum metal concentrations that are measurable in the field are not as low as those that were determined in the laboratory (Table II.1) due to attenuation of optical signals by the fiber bundle used in the prototype field monitor.

\section{TABLE VI.1 \\ Minimum Metal Concentrations Detected At Clemson And Estimates Of Minimum Detectable Concentrations.}

\begin{tabular}{|c|c|c|}
\hline Species & $\begin{array}{c}\text { Minimum Concentration } \\
\text { Measured at Clemson }\end{array}$ & $\begin{array}{c}\text { Estimated Minimum } \\
\text { Detectable Concentration }\end{array}$ \\
\hline $\mathrm{Cd}$ & $0.004 \mathrm{ppm}$ & $0.004 \mathrm{ppm}$ \\
\hline $\mathrm{Mn}$ & $0.014 \mathrm{ppm}$ & $0.001 \mathrm{ppm}$ \\
\hline $\mathrm{Pb}$ & $2 \mathrm{ppm}$ & $1 \mathrm{ppm}$ \\
\hline
\end{tabular}

\section{Metal Fractions in the Effluent}

Lead and cadmium concentrations in the effluent were typically between $0.1 \%$ and $1 \%$ of the values that would be achieved if all of the lead and cadmium in the waste feedstream went into the effluent. That is, only $0.1 \%$ to $1 \%$ of the metal waste input was emitted with the effluent, and the remaining $99 \%$ to $99.9 \%$ of the lead and cadmium in the waste feedstream stayed in the joule melter, presumably in the glass melt. For the same operating conditions, a much smaller fraction of the manganese was emitted with the effluent; typically less than $0.01 \%$ of the manganese in the inlet waste stream was measured in the stack flow. That is, the concentrations of lead, cadmium, and manganese in the effluent were not in the same proportions as the corresponding concentrations in the waste feed, which demonstrates that the fraction of the waste feed that is emitted differs for different metals.

By combining these estimates of the minimum detectable metal concentrations with the actual measured fractions of input metal waste that were observed in the effluent for the Clemson tests, we estimate that the prototype CEM could measure manganese in the effluent for less than $0.001 \% \mathrm{Mn}$ in the feedstream, cadmium for less than $0.0004 \% \mathrm{Cd}$ in the feedstream, and lead for about $0.05 \% \mathrm{~Pb}$ in the feedstream. 


\section{Factors Affecting Joule-Melter Emissions}

Although spectral emission was measured by the CEM for nearly all operating conditions, different spectral lines appeared for different operating conditions. That is, the CEM measurements showed that the species appearing in the effluent were a function of the way in which the joule melter was operated. The presence of an input waste feedstream and the composition of the input waste influenced the observed emissions, most notably during feedstream-startup transients.

Before the waste feedstream was first introduced at the start of the test series, the CEM detected significant optical emission from materials contained in the glass melt, most notably silicon, for which the concentration was on the order of $0.2 \mathrm{ppm}$ when no waste was being added. No significant emission from any of the eleven Clean Air Act metals was detected at the start of the week-long test series, even though metals had been introduced to the melt in low concentrations during the weeks before the Clemson tests.

When a waste feedstream was first introduced, optical emission from silicon increased sharply and then decreased before fluctuating about a mean signal level roughly an order of magnitude greater than it had been before the feedstream was started. The silicon concentration in the effluent was between 3 and $4 \mathrm{ppm}$ for two different average measurements at a steady waste flow. Other constituents of the glass melt that were measured under these conditions were boron $(0.1 \mathrm{ppm})$ and magnesium $(0.7 \mathrm{ppm})$.

We also observed large increases in optical emission when a stream of water was first introduced to the joule-melter (in place of the waste feedstream), followed by decay in optical emission after a few seconds to values typical of those observed when no waste was being added. This behavior suggests that the observed transient behavior (that is, a large increase in signal followed by a decrease and fluctuations about a lower mean steady-state value) was due to ejection of material from the glass melt when the liquid stream was first introduced, which diminishes after a few seconds of steady waste feed.

We also observed transient increases in metal emissions as the waste stream first started. At startup, metal emissions displayed a sharp initial spike, increasing and then decreasing again within a few seconds. After the initial spike, emissions fluctuated greatly about a lower mean value. Shown in Figure VI.4 is a sequence of spectra that shows the variation of plasma emission during such a waste-startup transient. Each frame of the sequence was obtained from a single laser pulse, starting with the "Background" spectrum obtained before the waste was introduced and continuing with spectra measured 1,3,6, and 9 laser pulses (approximately $0.5,1.5,3$, and 4.5 seconds) after the first appearance of strong optical emission from metals in the effluent. Plasma emission from cadmium, manganese, and lead increase strongly after waste is introduced but diminish within a few seconds.

Inferred cadmium concentrations in the effluent during a similar feedstream startup transient are shown in Figure VI.5. Here, the cadmium concentration rose to $16 \mathrm{ppm}$ immediately after the waste stream was started. At later times, the measured cadmium concentration generally fluctuated in a range between $1 \mathrm{ppm}$ and $5 \mathrm{ppm}$, although there were several excursions to both higher and lower concentrations. 


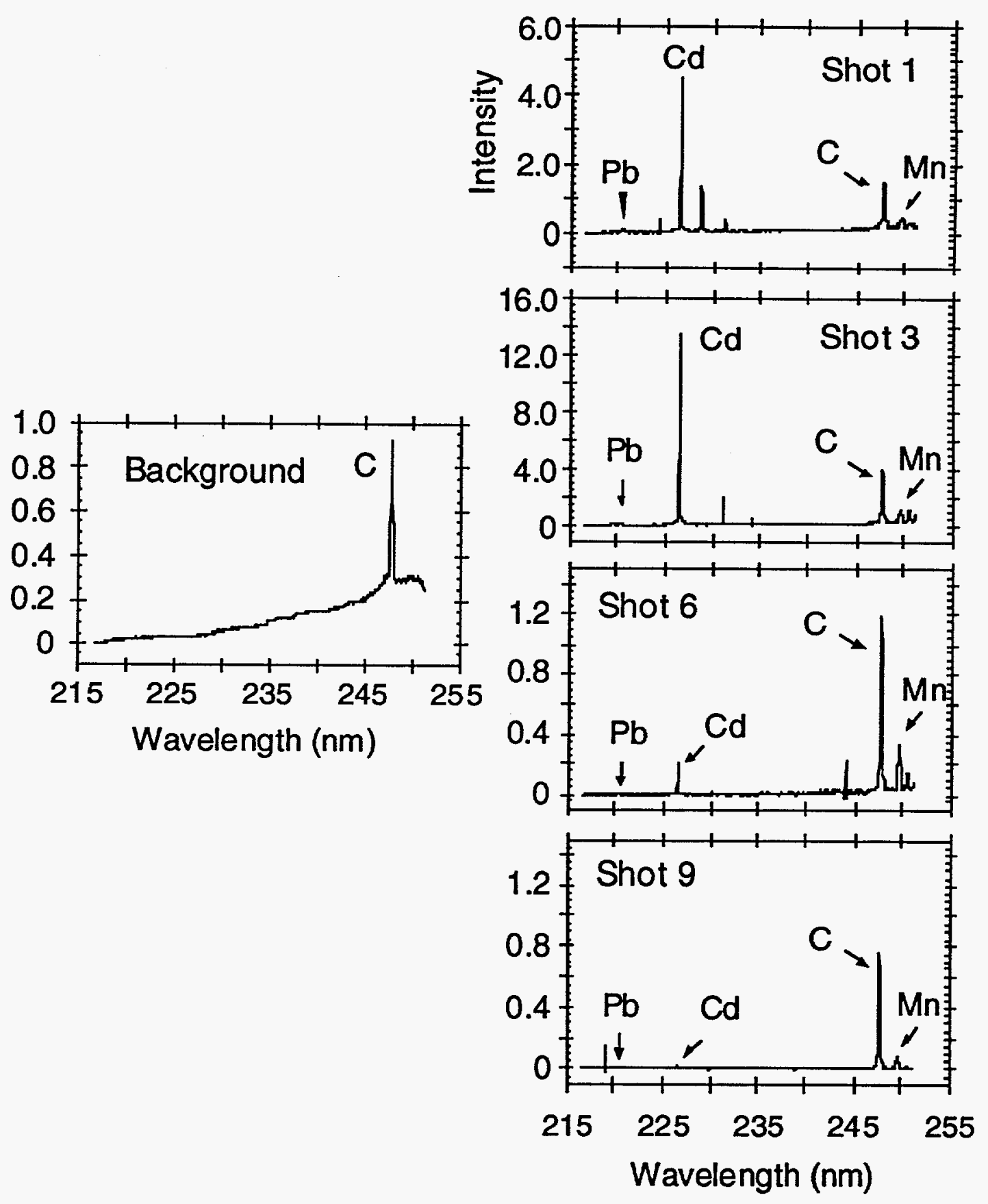

Figure VI.4 Sequence of spark spectra acquired as waste feed was first started. Each spectrum was acquired with a single laser pulse. On the left is a background spectrum measured before the feed was started. On the right are spectra for the first laser pulse after the wastestream was started; 3 pulses later; 6 pulses later; and 9 pulses later. The peak wavelengths for the elements are $247.7 \mathrm{~nm}$ for carbon, $220.4 \mathrm{~nm}$ for lead, and $226.5 \mathrm{~nm}$ for cadmium. (Note that the intensity scales are not the same for all spectra.) 


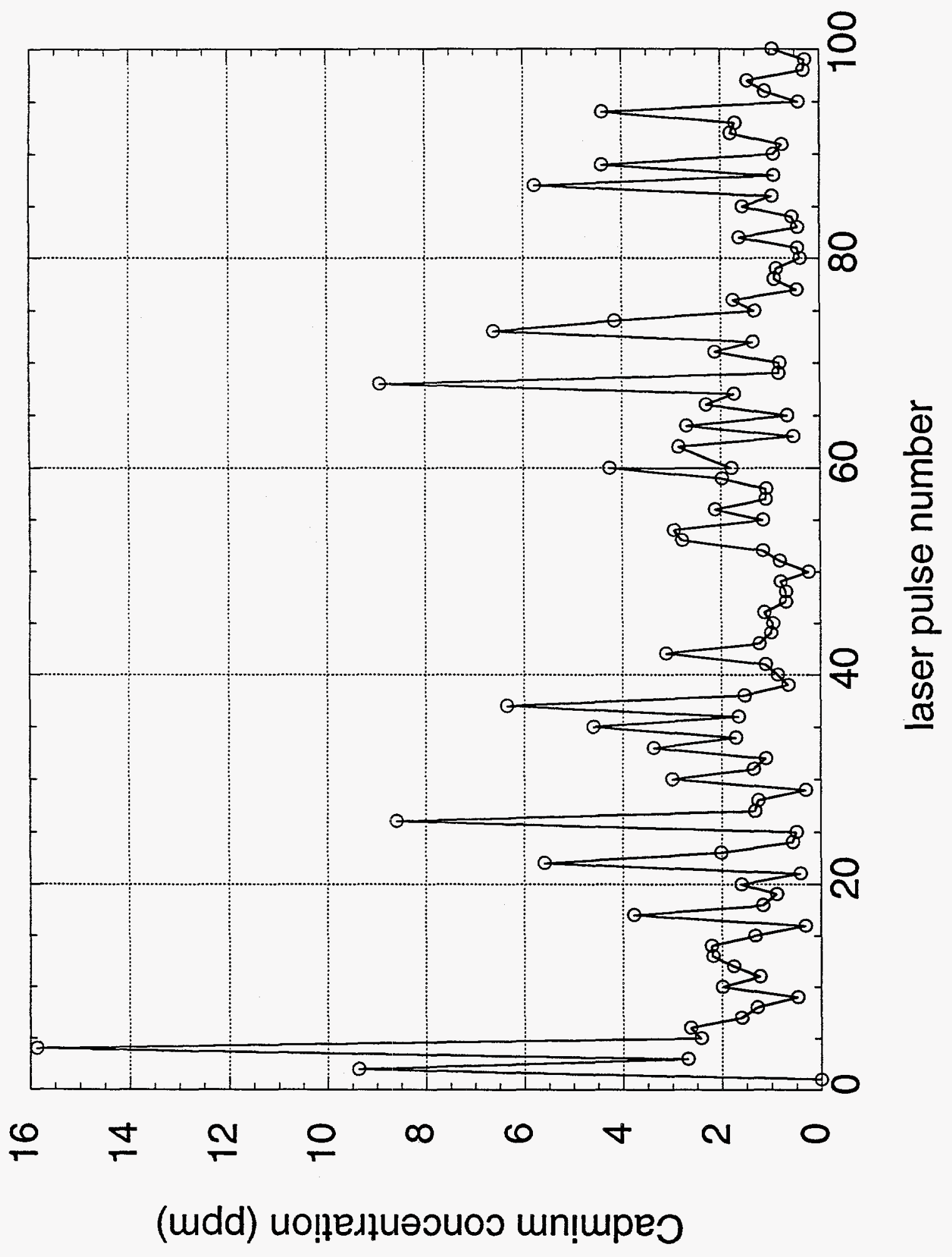

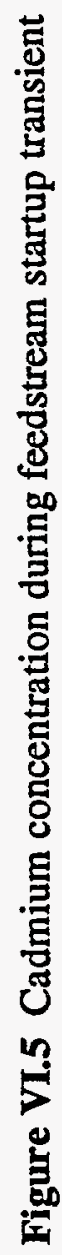


After the waste feed was shut off, emissions of metals decreased quickly, but, in some cases, low metal emissions could still be measured several hours after termination of the waste feed. In one particular case, cadmium was still measured at a concentration of $4 \mathrm{ppb}$ over three hours after wastes had last been introduced to the joule melter, this residual concentration was nearly four orders of magnitude lower than the $25 \mathrm{ppm}$ cadmium concentration that was measured when the waste was being introduced.

The above discussion has focused primarily on how emissions change when an operating parameter changes in real time. Because it was difficult to reproduce identical operating conditions in different experiments throughout the week (probably due to difficulties maintaining a fixed, steady waste stream flow) it was also difficult to run controlled experiments to examine how changes in a single operating parameter affect steady-state emissions. It was apparent, however, that the steady-state metal emissions were influenced by the rate at which the glass melt was stirred; higher stirring speeds appeared to result in lower metal emissions.

\section{SUMMARY}

This report describes the first field tests of a prototype, transportable, continuous emissions monitor for metals, which was designed and fabricated at Sandia National Laboratories under sponsorship of the U.S. Department of Energy. These tests demonstrate that laserspark-spectroscopy technology can be successfully integrated in a well-engineered system that is easy to transport, easy to set up, and which performs reliably in the field.

The actual field experiments, which were conducted at the Clemson University Vitrification Facility, successfully demonstrated that hazardous metals can be measured in the effluent from a thermal treatment facility that is processing metal-containing wastes. For the first time, we demonstrated the ability of a laser-spark CEM to determine metal concentrations through analysis of individual spectral lines in a complex, "real" effluent, where numerous spectral features from non-regulated species were also present. Well-isolated spectral lines of regulated metals were identified and analyzed, even in the presence of large abundances of interfering species such as iron, calcium, and silicon. We measured cadmium, lead, and manganese in the effluent during processing of a surrogate waste-water treatment slurry. These regulated metals were measured at sufficiently low concentration levels ( $4 \mathrm{ppb}$ to several hundred ppm) to demonstrate the utility of the laser-spark CEM for continuously verifying regulatory compliance.

The measurements also revealed how emissions change when operating parameters (such as waste feed rate or stirring speed) are changed, and the tests demonstrated the capability of the laser spark CEM to monitor transient effects in real time. Metal emissions were significantly greater during startup of the waste feedstream than when the waste feed had been flowing steadily for some time. Metal emissions also decreased rapidly as soon as the waste feed to the joule melter was shut off. These observations suggest that the nature of the interaction between the feedstream and the melt surface has a great influence on metal emission rates. Further experiments to investigate this interaction may be useful for understanding (and, ultimately, reducing) metal emissions from joule melters.

We are currently working to implement several improvements in a second-generation prototype CEM, which will be tested and demonstrated in the Spring of 1995. 


\section{REFERENCES}

1. G. A. Meyer, Spectroscopy 8, 28-34 (1993).

2. P. P. Woskov, D. R. Cohn, D. Y. Rhee, C. H. Titus, J. K. Wittle; and J. E. Surma, "Diagnostics for a Waste Remediation Plasma Arc Furnace", Massachusetts Institute of Technology Report PFC/JA-93-28, 1993.

3. J. A. Cooper, Fuel Processing Technology 39, 251-258 (1994).

4. P. Gorman, private communication, Midwest Research Institute, Kansas City, KS., November, 1994.

5. W. L. Flower, L. W. Peng, N. B. French, H. A. Johnsen, and D. K. Ottesen, "A Laser-Based Technique for Continuously Monitoring Metal Emissions From Thermal Waste Treatment Units," Proceedings of the 1994 International Incineration Conference (University of California, Irvine, 1994). 


\title{
APPENDIX A
}

\author{
Planned Test Sequence
}

Major Tasks

1. Power-up prototype monitor and establish operation

2. Obtain laser-induced breakdown, optimize strength of breakdown

3. Measure atomic emission from laser-induced breakdown, optimize signal

4. Establish wavelength calibration

5. Set aperture(s) to establish suitable signal levels

6. Determine appropriate signal-averaging parameters

7. Identify spectral features corresponding to species of interest in measured spectra

8. Perform chemometric analysis to determine species concentrations

9. Obtain extractive samples to characterize test conditions and instrument response

\section{Checklist for Field Test Operations}

Pre start-up:

- uncrate components

- check for visible damage

- check circuit boards in computer, instruments

- check electrical line on scope $(110,220)$

- connect components (cables, fiber) with probe head accessible

- fill laser power supply reservoir with deionized water

- connect gases, water - verify flows

- check for water leaks on laser, diode array

- check connections that were left in place during shipping

- check all instrument settings

- check spectrometer slits

- power up detector and data acquisition system

- check representative standard lamp spectra

- correct wavelengths

- correct signal levels

- power up laser, beam dump in place (cover in place or clear room)

- check power, maximize

- check for breakdown

- look for image on fiber (cover off - goggles on)

- check continuum spectrum

- check carbon emission line

- if no signal or bad signal, recheck and reposition fiber

- still bad? - check alignment with HeNe

- take complete set of standard lamp spectra

- install window in test section

- mount probe to test section 
Vitrification on, waste feed off

- for each spectral window:

- measure signal level, single shot or few-shot averages

- determine whether aperture setting is suitable, decide how to set

- check steadiness

- select averaging parameters appropriate to temporal variation

- take complete set of spark-emission spectra, alternating with discharge-lamp spectra at each spectrometer set point

- identify features by visual comparison to reference probe spectra, tabulated spectra

Vitrification on, waste feed on

- for each spectral window (emphasizing suspected components):

- measure signal level, single shot or few-shot averages

- determine whether aperture setting is suitable, decide how to set

- check steadiness

- select averaging parameters appropriate to temporal variation

- take complete set of spark-emission spectra, alternating with discharge-lamp spectra at each spectrometer set point

- identify features by visual comparison to reference probe spectra, tabulated spectra

Vitrification on, spiked waste feed

- for spectral windows appropriate to spiked components:

- measure signal level, single shot or few-shot averages

- determine whether aperture setting is suitable, decide how to set

- check steadiness

- select averaging parameters appropriate to temporal variation

- take spark-emission spectra, alternating with discharge-lamp spectra at each spectrometer set point

- identify features by visual comparison to reference probe spectra, tabulated spectra 


\section{UNLIMITED RELEASE}

\section{INITIAL DISTRIBUTION:}

MS 0755 A. E. Verardo, 6612

MS 9001 J. C Crawford,8000

Attn: E. E. Ives, 5200

R. J. Detry, 8200

W. J. McLean, 8300

L. A. Hiles, 8400

P. N. Smith, 8500

L. A. West, 8600

R. C. Wayne, 8700

T. M. Dyer, 8800

D. L. Crawford, 8900

MS 9004 M. E. John, 8100

MS 9202 T. Bramlette, 8106

MS 9103 W. L. Flower, 8111 (50)

MS 9103 R. F. Renzi, 8111

MS 9103 G. A. Thomas, 8111

MS 9103 D. Trujillo, 8111

MS 9103 C. Wood, 8111

MS $9410 \quad$ N. B. French, 8113

MS $9410 \quad$ J. C. Swearengen, 8113

MS 9214 R. W. Schmieder, 8113

MS 9053 K. R. Hencken, 8362

MS 9406 H. Hirano, 8412

MS 9404 H. Johnsen, 8713

MS 9404 L. Peng, 8713

MS 9404 D. Ottesen, 8713

MS $9404 \quad$ J. C. F. Wang, 8713

MS 9022 Mail Distribution (8533-1) for OSTI (2)

MS 9022 Mail Distribution (8533-1)/Technical Library Process, MS 0899 (7141)

MS 0899 Technical Library Processes Department, 7141(4)

MS 9018 Central Technical Files, 8532-2 (3) 